\title{
Noninvasive encapsulated papillary RAS-like thyroid tumor (NEPRAS) or encapsulated papillary thyroid carcinoma (PTC)
}

\author{
Pedro Weslley Rosario \\ Endocrinology Service, Santa Casa de Belo Horizonte, Minas Gerais, Brazil
}

In a recent case study, Ohba et al. [1] suggested that presence of papillae in absence of other criteria of malignancy and exuberant nuclear alterations (nuclear score 3 [2]) may not be sufficient for diagnosis of papillary thyroid carcinoma (PTC) and proposed the name "noninvasive encapsulated papillary RASlike thyroid tumor" (NEPRAS) to encompass the borderline nature of the diagnosis [1].

\section{CASE REPORT}

Based on the diagnostic proposal of Ohba et al. [1], we revised our cases of tumors $>1 \mathrm{~cm}$ previously diagnosed as PTC and that were encapsulated/well-delimited (thick, thin, or partial capsule or well-circumscribed with a clear demarcation from adjacent thyroid tissue) and noninvasive (absence of capsular or vascular invasion) $(\mathrm{n}=185)$. A total of 129 cases met all criteria for noninvasive follicular thyroid neoplasm with papillary like nuclear features (NIFTP) [3], and 11 were excluded due to the presence of papillae [4]. These and an additional 35 cases were initially considered encapsulated PTC, and nine were diagnosed as poorly differentiated carcinoma or an aggressive PTC subtype. Among the 11 cases not considered NIFTP due to the presence of papillae, eight had exuberant nuclear alterations (nuclear score 3 [2]). The three reported here had a nuclear score of 2 and would be reclassified from encapsulated PTC to NEPRAS [1]. Ultimately, we analyzed 43 cases of noninvasive encapsulated PTC and three of NEPRAS. None of the tumors carried the BRAF $F^{\mathrm{V} 600 \mathrm{E}}$

Received: January 22, 2020 Revised: February 4, 2020

Accepted: February 5, 2020

Corresponding Author: Pedro Weslley Rosario, MD, PhD

Santa Casa de Belo Horizonte, Rua Domingos Vieira, 590, Santa Efigênia. CEP 30150-

240, Belo Horizonte, MG, Brasil

Tel: +55-31-32388819, Fax: +55-31-32388980, E-mail: pedrowsrosario@gmail.com mutation, which was the only mutation investigated. Thus, the three cases diagnosed as NEPRAS met all criteria presented in Table 1. The characteristics of the patients are shown in Table 2.

None of these cases exhibited metastasis at presentation, were treated with radioiodine, or were maintained under TSH suppression. Excellent response to initial therapy was achieved in all three cases. No recurrence was detected after 36, 48, and 60 months of follow-up. Because of the small number of NEPRAS cases $(n=3)$, we did not perform statistical comparison between NIFTP and noninvasive encapsulated PTC, analyzing only patients with lymph node metastases at presentation and/or recurrence.

\section{Ethics statement}

The study was approved by the research ethics committee of Santa Casa de Belo Horizonte (No. 21968013.8.0000.5138). Informed consent was obtained from all individual participants included in the study.

\section{DISCUSSION}

Well-delimited or encapsulated thyroid neoplasms without vascular or capsular invasion or necrosis, with low mitotic index

Table 1. Criteria for diagnosing "noninvasive encapsulated papillary RAS-like thyroid tumor"

\begin{tabular}{l}
\hline Criteria \\
\hline Presence of papillae \\
Encapsulation or clear demarcation \\
No vascular or capsular invasion \\
$<30 \%$ solid/trabecular/insular growth pattern \\
No tumor necrosis or high mitotic activity [2] \\
Nuclear score 2 [2] \\
Lack of BRAF
\end{tabular}


Table 2. Characteristics of three patients with NEPRAS

\begin{tabular}{|c|c|c|c|c|c|c|c|c|}
\hline Sex & Age (yr) & Presentation & $\begin{array}{l}\text { Tumor } \\
\text { size }(\mathrm{cm})\end{array}$ & $\begin{array}{l}\text { Nuclear } \\
\text { score [2] }\end{array}$ & $\begin{array}{l}\text { Papillae } \\
\text { (\%) }\end{array}$ & $\begin{array}{l}\text { Associated } \\
\text { thyroid pathology }\end{array}$ & Initial therapy & TNM/AJCC \\
\hline$F$ & 35 & $\begin{array}{l}\text { Atoxic uninodular disease, } \\
\text { US: hypoechoic solid nodule } 4.5 \mathrm{~cm}^{\mathrm{a}} \text {, } \\
\text { FNA: Bethesda IV }\end{array}$ & 4 & 2 & $<1$ & $\begin{array}{l}\text { Normal extranodular hyroid } \\
\text { parenchyma }\end{array}$ & $\begin{array}{l}\text { Total } \\
\text { thyroidectomy }\end{array}$ & $\begin{array}{l}\text { T2NxMO/ } \\
\text { stage I }\end{array}$ \\
\hline $\mathrm{F}$ & 43 & $\begin{array}{l}\text { Atoxic multinodular disease; } \\
\text { US: hypoechoic solid nodule } 2.5 \mathrm{~cm}^{\mathrm{a}} \text {, } \\
\text { two nodules } 0.6 \text { and } 0.5 \mathrm{~cm} ; \\
\text { FNA: Bethesda III }\end{array}$ & 2.2 & 2 & 1 & Benign nodular disease & Lobectomy & $\begin{array}{l}\text { T2NOMO/ } \\
\text { stage I }\end{array}$ \\
\hline M & 48 & $\begin{array}{l}\text { Atoxic uninodular disease, } \\
\text { US: hypoechoic solid nodule } 4 \mathrm{~cm}^{\text {a }} \text {, } \\
\text { FNA: Bethesda IV }\end{array}$ & 3.5 & 2 & 1 & $\begin{array}{l}\text { Normal extranodular thyroid } \\
\text { parenchyma }\end{array}$ & Lobectomy & $\begin{array}{l}\text { T2NxMO/ } \\
\text { stage I }\end{array}$ \\
\hline
\end{tabular}

NEPRAS, noninvasive encapsulated papillary RAS-like thyroid tumor; AJCC, American Joint Committee on Cancer; F, female; US, ultrasonography; FNA, fineneedle aspiration; M, male.

aWithout suspicious findings for malignancy (irregular margins, microcalcification, taller-than-wide shape).

and $<30 \%$ solid/trabecular/insular growth patterns, and with nuclear alterations characteristic of PTC (nuclear score 2 or 3 [2]) are diagnosed as NIFTP or encapsulated PTC depending on the presence (PTC) or absence (NIFTP) of papillae [2]. NIFTP is a borderline tumor that requires no additional surgical complementation, adjuvant therapy with radioiodine, TSH suppression, or monitoring with serum thyroglobulin and neck ultrasound after complete resection [5]. In contrast, encapsulated PTC is a malignant tumor that must be staged. Even when restricted to the thyroid, surgical complementation, radioiodine ablation, long-term follow-up, and TSH suppression may be necessary depending on tumor size and patient age.

Although the present study comprises only case reports, the patients supported the observations of Ohba et al. [1] that lesions that do not exhibit other malignancy criteria or exuberant nuclear alterations despite the presence of papillae may be reclassified from malignant (encapsulated PTC) to borderline (NEPRAS). This proposal would result in changes of patient management, with the same implications as those seen for the change from noninvasive encapsulated follicular variant of PTC to NIFTP [2].

\section{ORCID}

Pedro Weslley Rosario:

https://orcid.org/0000-0002-5190-382X

\section{Conflicts of Interest}

The authors declare that they have no potential conflicts of interest.

\section{Funding}

No funding to declare.

\section{REFERENCES}

1. Ohba K, Mitsutake N, Matsuse M, et al. Encapsulated papillary thyroid tumor with delicate nuclear changes and a KRAS mutation as a possible novel subtype of borderline tumor. J Pathol Transl Med 2019; 53: 136-41.

2. Nikiforov YE, Baloch ZW, Hodak SP, et al. Change in diagnostic criteria for noninvasive follicular thyroid neoplasm with papillarylike nuclear features. JAMA Oncol 2018; 4: 1125-6.

3. Rosario PW, Mourao GF, Nunes MB, Nunes MS, Calsolari MR. Noninvasive follicular thyroid neoplasm with papillary-like nuclear features. Endocr Relat Cancer 2016; 23: 893-7.

4. Rosario PW. Diagnostic criterion of noninvasive follicular thyroid neoplasm with papillary-like nuclear features (NIFTP): absence of papillae. Hum Pathol 2019; 83: 225.

5. Haugen BR, Sawka AM, Alexander EK, et al. American Thyroid Association Guidelines on the Management of Thyroid Nodules and Differentiated Thyroid Cancer Task Force review and recommendation on the proposed renaming of encapsulated follicular variant papillary thyroid carcinoma without invasion to noninvasive follicular thyroid neoplasm with papillary-like nuclear features. Thyroid 2017; 27: 481-3. 